\title{
GIS Identifies Elderly Healthcare Centre Future Planning: A Case Study of Local Areas in Northeast of Thailand
}

\author{
Niruwan TURNBULL ${ }^{\mathrm{a}, 1}$, Jaturong SOM-AD ${ }^{\mathrm{b}}$, Savitree Ratanaopad SUWANLEE ${ }^{\mathrm{b}}$ and \\ Adisorn WONGKONGDECH ${ }^{\mathrm{a}}$ \\ ${ }^{a}$ Faculty of Public Health, Mahasarakham University, Thailand \\ ${ }^{b}$ Faculty of Humanities and Social Sciences, Mahasarakham University, Thailand
}

\begin{abstract}
Spatial density measures are an important tool for future healthcare planning, particularly in Northeast Thailand where the ageing population has rapidly increased for a decade. The objective of this study was to determine the relationship of geographic and elderly population density in Chiang Yuen district, Mahasarakham province, to ascertain suitable areas for elderly healthcare centres. The data of the elderly located in the villages were collected by the Global Position System (GPS) using Kernel density method to employ the analysis of population density, and GIS for healthcare mapping, and Analytical Hierarchy Process (AHP) as multiple criteria decision-making tools. Factors were determined by using the overlay analysis method, where social, physical and economic factors were variables of interest that were used for the analysis of suitable areas for Elderly Healthcare Centres. The results revealed that the spatial density of the elderly population could be divided into four levels: Low density for the agriculture areas, medium density for agricultural areas including small villages. High density for the areas near communities and public area services and highest density for the centre of towns. The most suitable area was an area with many elderly inhabitants in the community, near transportation routes including main highways leading to other areas. In conclusion, the results confirmed that the density of elderly and proximity to both local stores and transport would make the lower part of Chiang Yuen Sub-district a suitable area to establish a healthcare centre for the elderly, therefore, the authorities and stakeholders should recognise this in planning.
\end{abstract}

Keywords. Elderly, Healthcare planning, Geographic Information System (GIS), Health Information, Healthcare Centre

\section{Introduction}

Thailand has gone through a complete process of aging in the population, with a rapid increase in the population of the elderly since 2005 (more than $10 \%$ of the total population is elderly) and it is expected that by 2025 , the elderly will be more than $20 \%$ of the population. In 2010, the number of elderly was 10.7 per cent or 7.02 million people, and is 12.8 per cent, which is a rapid increase in proportion [1]. Humphreys

${ }^{1}$ Corresponding Author, Niruwan Turnbull, Faculty of Public Health, Mahasarakham University; E-mail: niruwan.o@msu.ac.th. 
(2010 p. 82-83) reported that in Thailand "The proportion of elderly persons in the total population was expected to reach $14 \%$ in $2015,19.8 \%$ in 2025 and nearly $30 \%$ by 2050". Thai government was working on the national level to directly support the elderly with a retirement pension for insured workers under the social security system and savers under a planned National Savings Scheme, however, it was insufficient [2]. The rapid increase in older people, Thai authorities need to be concerned for the elderly population, especially in the poorest areas such as Northeast Thailand Maha Sarakham province (MSK) is a local area in the Northeast of Thailand, which has large areas of the poorest economically. This province has a population of about 900,000 people and there are about 90,200 elderly [1]. Chiang Yuen District is a district in MSK, which has about 8,325 elderly people. Most of the elderly suffered from chronic diseases such as diabetes, high blood pressure, heart disease and gout, and need to be cared for a nearby person as well as by government agencies, which need to maintain a budget to provide proper health service. MSK has not set up an appropriate elderly healthcare centre; therefore they need an information management system to find suitable areas for a indicating located healthcare.

\section{Material and Methods}

\section{Research Areas}

Chiang Yuen district in Maha Sarakham province was selected as the research area from local areas in Northeast Thailand. It is an area of 289 square kilometres adjacent to Kalasin province and Khon Kean province and separated into 8 districts and 116 villages. (see figure 1). Most villagers were agricultural workers and young people go out to work at industrial zone. These young workers come back home in one or two times in a year.

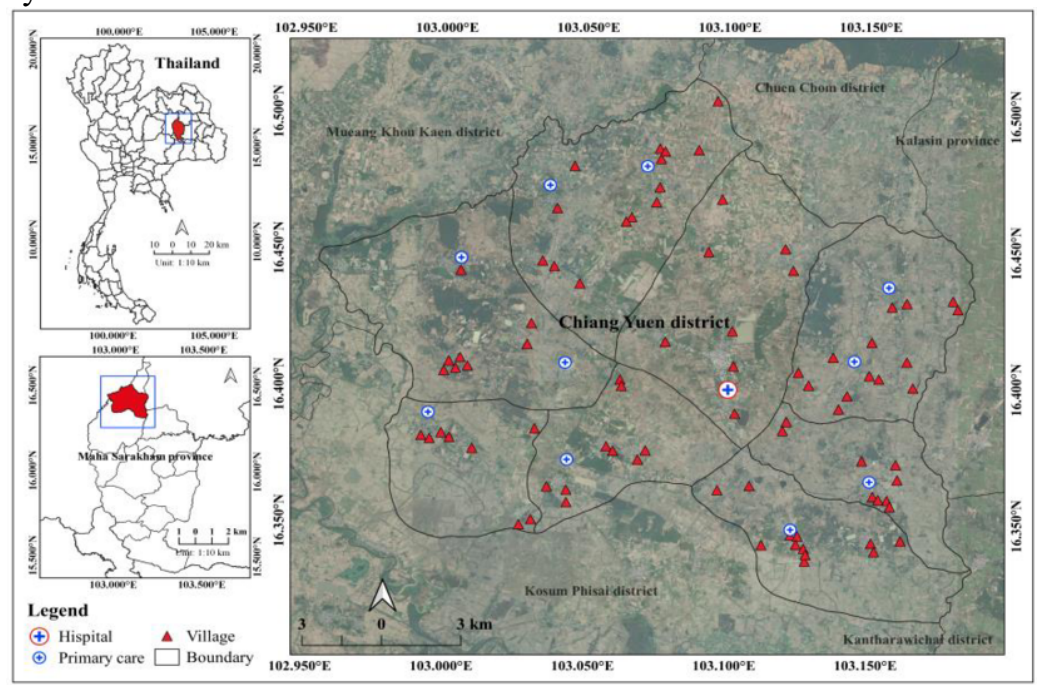

Figure 1. Study area 


\section{Data Collection and Analysis}

The data for healthcare identification used both primary and secondary data, from the field work survey during $1^{\text {st }}$ June- $25^{\text {th }}$ July 2017 including: Location of the elderly (coordinates: $\mathrm{X}, \mathrm{Y}$ ), creation of interview forms for all elderlies (a total of 8,325 people) including date of interview, name, address, gender, and age using GPS handheld to acquire the houses of elderly and never been of survey by health service in Thailand. The Barthel Activities of Daily Living (ADL) as questionnaire form was generated by Ministry of public health in Thailand and this form contain ten questions [3].

The research analysed the distribution of density and identified the optimal sites for the establishment of a Health Centre to improve the quality of life for the elderly. The data was collected and analysed in four sections including: 1) a location database, 2) weight analysis using AHP method, 3) Kernel density analysis, and 4) managing the influence factors for setting up new healthcare centres. The details are shown as follows:

1) Locations of the elderly collected from ground survey as indicate above and then we generated the elderly points as Geo-database of GIS data for mapping density map. In addition, the database was referred UTM WGS 1984 zone $48 \mathrm{~N}$ (Northeast Thailand) of coordinate system.

2) Location of the hospitals, including 11 Health Promoting Hospitals (primary care) and one general hospital were collected from survey and created in Geospatial database for GIS analysis.

3) Data for the elderly was separated into three groups based on ADL rule to evaluate their activities including a community mobile group, a home-based group, and a bedridden group [3], which was used to identify the distribution of the elderly density map.

\section{Results and Findings}

\section{Location and density of the elderly survey}

The statistical data for the elderly aged 60 years and over in 2017 from Chiang Yuen District contained 8,325 elderly people .The study presented the position of the elderly in the sub-districts as shown in table 1.

Table 1. The field survey of the position of the elderly.

\begin{tabular}{rcc}
\hline Sub-districts & Population & Percentage \\
\hline Chiang Yuen & 1,790 & 21.5 \\
Ku Thong & 1,479 & 17.8 \\
Suea Thao & 1,139 & 13.7 \\
Don Ngoen & 959 & 11.5 \\
Nathong & 848 & 10.2 \\
\hline
\end{tabular}

\section{Determination of areas for establishing an Elderly Healthcare Centre}

The relevance of the factors revealed that the social factors were most important at 45.24 per cent. These including the density of the elderly, healthcare service places and religious service places at values of 13, 12 and 8 respectively .Secondly were physical factors at 37.17 per cent, which consist of the proximity to the town. Thirdly were economic factors, at 17.59 per cent, associated with One Tambon One Product Centres (OTOP), convenience stores, banks, and pharmacies. The determination of weighted 
values, priority of each factor and creation of a spatial factor database to bring all the factors to overlap the spatial data together with Simple Additive Weighting Methods (SAW), showed the suitability of areas for setting up an Elderly Healthcare Centre dividing into 4 levels. (see Figure 2)

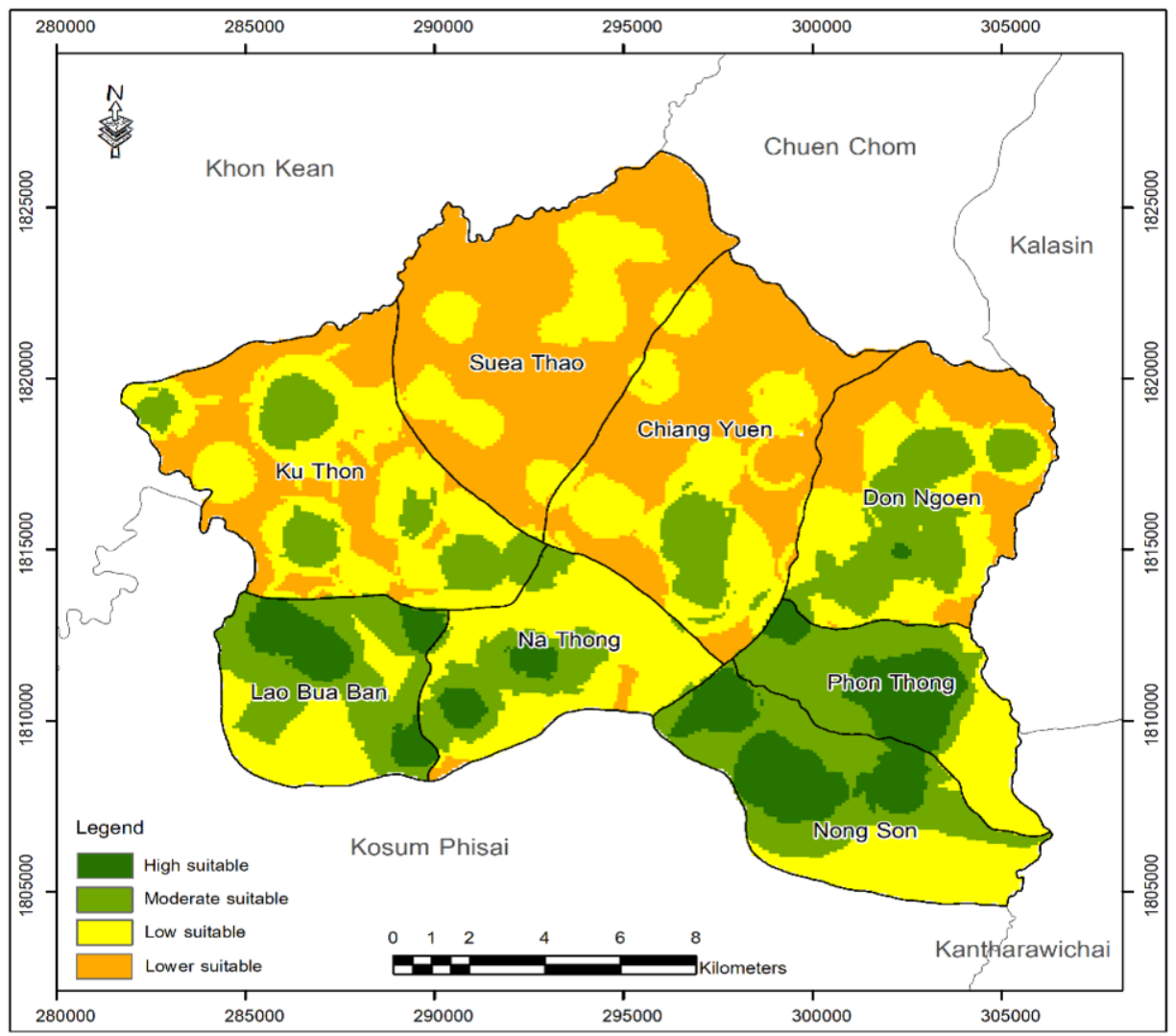

Figure 2 The suitability areas for the Elderly Health Centre

\section{Discussion}

Creating GIS in healthcare planning and management service for the elderly in developing countries is a crucial issue. Healthcare data with GIS assets can simplify tasks, assist with planning and management, and lead to more efficient decisionmaking [4]. This has been discussed in several researches [5-9]. Black also indicates that access to healthcare is a crucial concern of an overall health system and has direct impact on the barrier of diseases in the developing world [10] .This research found four areas were suitability place to setup healthcare centre, however, the lower part of the district including elderly inhabitants, corner stores and accessibility to travel to the other part were involved for planning decision to establish the elderly healthcare centre.

Employing GIS in healthcare has benefited people for many years, such as to develop a web-based GIS for public healthcare systems [11], or even for a patients referral system [12]. It can reform government and societal functions by uniting 
disparate information sets and displaying them as a simple mechanism for people to understand [13]. Indeed, local areas like northeast Thailand needs to create the healthcare centre for elderly people, even though Thai has set up local hospital, calls Health Promotion Hospital (Songsermsugapap), which still need more healthcare professionals to look after the elderly due to physical disability as well as psychology support in some cases.

\section{Conclusion}

It is of concern that the most suitable areas to construct an Elderly Healthcare Centre need a high number of elderly inhabitants in the town, including convenient public facilities such as religious places, schools, highway transportation, grocery shops, health service places, and government buildings. It was concluded that locations in the lower part of Chiang Yuen district, namely Loa Bua Ban, Nong Son, Phon Thong and Don Ngoen sub-districts were suitable areas. This result can be implied to other areas in case of planning to construct healthcare centre especially for older people.

\section{References}

[1] Ministry of Public Health, T. Elderly population. 2018 [cited 201914 October]; Available from: https://hdcservice.moph.go.th/hdc/reports/report.php?source=pformated/format1.php\&cat_id=696 6b0664b89805a484d7ac96c6edc48\&id=953a2fc648be8ce76a8115fbb955bb51.

[2] Humphreys, G., The health-care challenges posed by population ageing. 2012, SciELO Public Health.

[3] Nongluck Pagaiya, S.S.a.S.Y., Long term care for the elderly. Foundation of Thai Gerontology Research and Development Institute, 2008.

[4] Melnick AL, Introduction to geographic information systems in public health. 2002: Jones \& Bartlett Learning.

[5] Scerpella DL, et al. Implications of Geographic Information Systems (GIS) for targeted recruitment of older adults with dementia and their caregivers in the community: A retrospective analysis. Contemporary clinical trials communications. 2019. 14: 100338.

[6] Fradelos EC, et al. Health based geographic information systems (GIS) and their applications. Acta Informatica Medica, 2014; 22(6): 402.

[7] Sharma AK. Role of GIS in Health Management Information System and Medical Plan: A Case Study of Gangtok area, Sikkim, India. International Journal of Environment and Geoinformatics. 2015; 2(1): 16-24.

[8] Murad AA. Creating a GIS application for health services at Jeddah city. Computers in Biology and Medicine. 2007; 37(6): 879-889.

[9] Musa GJ, et al. Use of GIS Mapping as a Public Health Tool--From Cholera to Cancer. Health services insights. 2013; 6: HSI. S10471.

[10] Black M. et al. Using GIS to measure physical accessibility to health care. World Health Organization. 2004: 3-4.

[11] Abdullahi F, Lawal M, and Agushaka J. Design and implementation of a Web-based GIS for public healthcare decision support system in Zaria metropolis. Int J Res Rev Appl Sci. 2010; 4(4): 435-439.

[12] Abdullahi F and Hassan T. Design And Implementation Of A Web-Based GIS For Patients Referral To Hospitals In Zaria Metropolis. International Journal of Research and Reviews in Applied Sciences. 2011; 8(1).

[13] Saugene Z, Juvane M, and Ernesto I. Factors affecting geographic information systems implementation and use in healthcare sector: the case of OpenHealthMapper in developing countries. Spatially Enabling Government, Industry and Citizens: Research and Development Perspectives. GSDI Association Press, Needham, 2012. 